\title{
To study the correlation of symptoms of angina with the diagnosis of ST Segment Elevation Myocardial Infarction (STEMI)
}

\author{
V.R. Mujeeb ${ }^{1}$, Jambunathan $P^{2}$, Tyagi $A^{3}$ \\ ${ }^{1}$ Dr. V.R. Mujeeb, Senior Advisor (Medicine \& Gastroenterology), ${ }^{2}$ Dr Prashant Jambunathan, Resident Medicine, \\ Command Hospital (Southern Command), Wanorie, Pune, ${ }^{3}$ Brig (Dr) Arun Tyagi, Professor \& Hod, Department of \\ Medicine, DVVPF'S Medical College, Vilad Ghat, Ahmednagar, Maharashtra, India.
}

Address for Correspondence: GP Capt (Dr) V.R. Mujeeb, Medicine, DNB (Gastroenterology), Senior Advisor (Medicine \& Gastroenterology), Command Hospital (Southern Command), Wanorie, Pune (Maharashtra), Email: aruntyagidr@gmail.com

\begin{abstract}
Introduction: Chest pain is amongst the commonest causes of visits to the emergency department. A rapid assessment with a prompt evaluation with an electrocardiogram clinches the diagnosis in most cases. However, with ever increasing strain on our limited resources, patient reported symptoms are central to initial assessment and must decide the course of action. Although considered ominous signs requiring further, often emergent, assessment, data on correlation of symptoms of angina with ST segment elevation is limited in contemporary literature. Methodology: 230 patients with biomarker proven ST segment elevation myocardial infarction (STEMI) were studied and assessed for frequency of the four, patient reported, cardinal symptoms of angina, namely retrosternal chest discomfort, diaphoresis, palpitations and radiation. We assessed the relative presence or absence of these supposedly cardinal symptoms of angina and set out to classify the most important symptoms of angina. Results: Our study shows that presence of three or more above symptoms is associated with a much higher possibility of an actual STEMI as opposed to only one symptom. Furthermore, a measurable increase in the probability of MI exists, when the number of patient reported symptoms increases from none to all four, as mentioned above. Though the study also reaffirmed the association between hypertension and Type 2 Diabetes Mellitus with acute coronary syndromes, our study was neither powered, nor designed to study this association. Conclusions: Patient reported symptoms have a direct and additive correlation with STEMI. A quick but detailed history in the emergency department is of paramount importance to identify high risk patients.
\end{abstract}

Key words: Angina, Acute Coronary Syndrome, Chest Pain, STEMI

\section{Introduction}

Chest pain forms about $15 \%$ of all visits to the emergency room, with about $13 \%$ of these being diagnosed as acute coronary syndrome. Of these diagnosed cases, $2 \%$ will have an adverse event, which includes a recurrence or early fatality, or both [1-3]. Myocardial infarction occurs due to a disparity between myocardial supply and demand. This imbalance may be due to atherosclerosis with a possible plaque rupture, vasoconstriction or vasospasm. Furthermore, aortitis, spontaneous coronary dissection, coronary embolus from an intracardiac or extra cardiac source or a

Manuscript received: $15^{\text {th }}$ December 2016

Reviewed: $24^{\text {th }}$ December 2016

Author Corrected: $30^{\text {th }}$ December 2016

Accepted for Publication: $7^{\text {rd }}$ January 2017 congenital abnormality of coronary vessels could compromise myocardial blood flow. Despite advances in diagnosis and early intervention (early exercise testing, radionuclide scanning, cardiac CT and novel biomarkers), myocardial infarction remains a major public health problem [3].

Rapid diagnosis remains the mainstay and could mean the difference between life and death. As the obesity, epidemic rages on in the Indian subcontinent, with modifiable coronary risk factors being on the steady rise, the incidence of MI is expected to rise in the next few years in our country. This directly correlates with ever increasing health care costs, both for initial 
diagnosis (e.g. Biomarkers, 2D echo, Cardiac CT) and further treatment (PCI or PTCA/CABG). Chest pain units and clinics, while crucial to our setup, are part of the reason for ever increasing costs in the healthcare sector [4].

While modern investigative techniques are reliable to a very high degree, a reasonable pre-test possibility must be established [5].

In the emergency department, the typical chest pain patient may report a myriad of symptoms. These descriptions are almost as numerous and varied as the patients themselves. Assessment of risk of major coronary events is crucial in these patients [6]. However, there are a few ominous symptoms and signs which one must take into cognizance, early in the diagnostic process. These include retrosternal chest pain with or without radiation, sweating (diaphoresis) and palpitations. Presence or absence of these symptoms often sways the clinician's decisions in various directions [7]. The definition of angina, as introduced by Heberden in the $18^{\text {th }}$ century stands unchallenged to date.

\section{Aims \& Objectives}

1. To study the relevance of these time-tested symptoms of angina and sought to assess if expensive biomarkers were indicated in patients with very few or none of these symptoms.

2. This study was also carried out with a view to reduce overenthusiastic evaluation of patients who, both historically and clinically, are unlikely to have an acute coronary event.

\section{Methods}

Study Population- We studied 230 patients presenting to the emergency department of a tertiary care hospital with 'typical' symptoms as described above, with evidence of myocyte necrosis as evidenced by a positive cardiac biomarker (cardiac troponins). Most of these patients underwent a percutaneous coronary intervention, while others underwent a CABG. We collected our data through the process of routine history taking which formed part of the emergency room protocol (Algorithm 1).

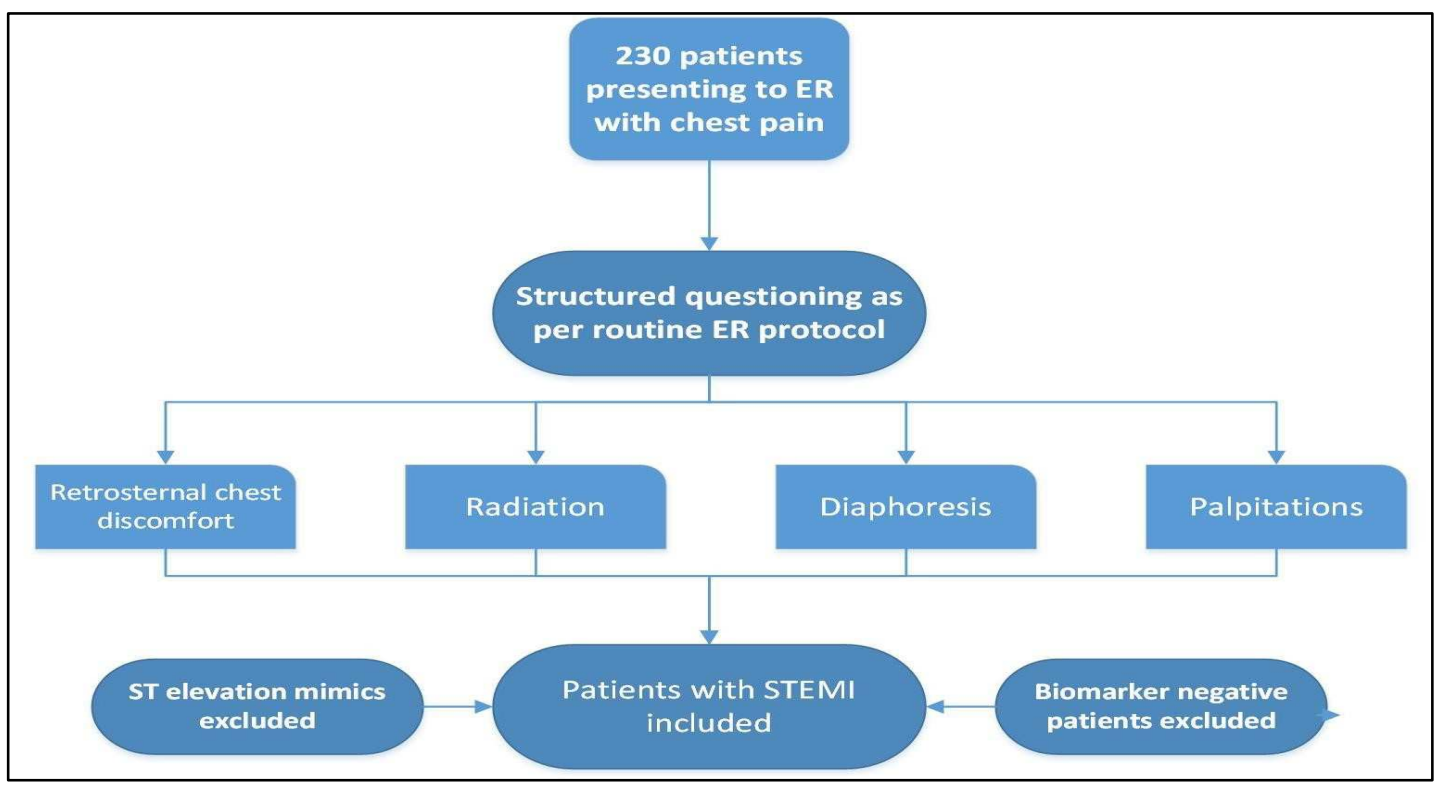

Algorithm-1: ER Protocol for Chest Patients

Study Design- The study was a single center, observational study lasting 14 months. Since every patient received treatment according existing standard of care, written consent was waived. All patients with ST elevation and positive biomarkers were included, while those who had non-angina chest pain (or other sinister causes, such as PTE or aortic dissection) or non-MI ST elevation mimics (Pericarditis, Brugada syndrome, apical ballooning) were excluded. Patients with non-ST segment elevation MI and unstable angina were also excluded, as per the original research question. There 
was only a single point of contact and no follow up was deemed necessary as patient reported symptoms were central to the study. All patients were then referred to a PCI capable center according to standard protocol [8-11].

Study Outcomes- Statistical association of classical symptoms of angina with STEMI in biomarker proven patients, as is the existing teaching and practice, was the singular outcome measured in this study.

Statistical Analysis- For the four symptoms of Angina and its association with ST elevation, the Chi square test for goodness of fit was used. The gradual increase in frequency of the criteria 'None', any one, 'any two', 'any three' \& 'all four' suggests that the possibility of myocardial infarction increases with the increase in cardinal symptoms i.e. retrosternal Chest discomfort and its radiation, diaphoresis and palpitations. The difference in occurrence of STEMI with three or symptoms was not significant.

Safety- We wish to emphasize that history taking was the key data collection tool, with all patients receiving existing standard of care as per guidelines. The technique of data collection through history taking ensured prompt emergency care and further referral as deemed necessary with any delay.

Limitations-While we set out to explore and investigate the real time mathematical association (if any) between symptoms and actual coronary interventions, we fully understand the limitations of a data set based on patient reported symptoms in an emergency room. Interviewer bias could not be avoided; all the questions were direct and precise, which may be construed as leading. However, we also identify that line of questioning is universal and is also present outside the realm of this study during routine clinical practice.

\section{Results}

We found a linear relationship between presence of three or more symptoms and the development of ST segment elevation myocardial infarction. However, our analysis fails to show a significant increase in the probability of STEMI if only two or less symptoms are present. Retrosternal chest comfort was the most common symptom $(90.4 \%)(\mathrm{P}<0.001)$ in these patients followed by diaphoresis. Both radiation $(34.3 \%)(\mathrm{P}<0.001)$ and palpitations $(27.3 \%)(\mathrm{P}<0.001)$ were much less common than expected. Based on this data, we infer that while looked at in isolation these symptoms may not provide statistically significant diagnostic information. However, when viewed holistically they represent a wealth of diagnostic information (Table 1).

Table-1: Significance of Anginal Symptoms.

\begin{tabular}{|c|c|c|}
\hline Frequency distribution of symptoms of angina & Absent \\
\hline Symptoms & Present & 34.7 \\
\hline Diaphoresis & 64.3 & 72.7 \\
\hline Palpitations & 27.3 & 65.6 \\
\hline Radiation & 34.3 & 9.5 \\
\hline
\end{tabular}

\begin{tabular}{|c|c|c|c|}
\hline Symptoms & $\begin{array}{c}\text { Percentage occurrence of } \\
\text { STEMI }\end{array}$ & \multicolumn{2}{|c|}{ Test Statistics } \\
\hline None & 1 & Chi-Square $-97.565^{\mathrm{a}}$ \\
\hline Any one & 23 & DF & 4 \\
\hline Any two & 53 & P value & 0.001 \\
\hline Any three & 80 & $\begin{array}{r}\text { a - No cells have expected frequencies less than 5. The minimum } \\
\text { expected cell frequency is 46.0. }\end{array}$ \\
\hline Any four & 73 & \multicolumn{2}{|c|}{} \\
\hline
\end{tabular}




\section{Discussion}

The exact mechanism of retrosternal chest pain in STEMI remains unclear. Nonmedullated sympathetic fibers that are found along the coronary arteries are known to be the afferent supply, which enter the spinal cord at the $\mathrm{C} 8$ to $\mathrm{T} 4$ segments [1]. The pain signals are conveyed to the thalamus and cerebral cortex. Also, anginal pain may be referred to shared segmental dermatomes. The precipitating factors and pattern of disappearance of said pain or discomfort are of equal (or even greater) significance. The precipitating factors are generally exertion, stress, eating or cold weather.

The patient generally conveys the feeling through clenched fist to his chest (Levine's sign). The duration is generally more than 30 minutes. Wide variations exist and are partially helpful in the clinical decision making process. Pain that lasts a few seconds or a few months is typically non-anginal. While the infarcted myocardium share a common pathophysiologic basis i.e. ischemia and subsequent necrosis, the so called 'typical' symptoms are often not present.

This is probably a regular cause of diagnostic dilemmas which ensue in the emergency room. This, when added to the confusion faced by the emergency room physician with borderline ECGs, compounds the problem [7]. Lack of meticulous history taking can lead to unnecessary expenses for the patient. We have demonstrated that this specific pattern of retrosternal pain is present in up to $90 \%$ of patients. It's utility as a 'rule in' criteria have been adequately amplified through this study. The absence of this discomfort doesn't rule out the presence of a sinister underlying cardio-respiratory pathology.

Typical angina and sweating was found to be reliable indicator of STEMI according to one study [12]. Our findings are concurrent, with sweating distributed in frequency in second position, next to retrosternal discomfort. These symptoms may also be incorporated in automated systems for diagnosis for STEMI [16]. Another study showed that patient reported symptoms were reliable in only $50 \%$ of cases [13]. Patient descriptions for angina symptoms were not found in accordance to the Diamond and Forester scale for typicality of angina [14]. The duration between onset of symptoms and reporting to the hospital was also found to be significant [15].

\section{Conclusion}

Symptoms and signs correlate with occurrence of STEMI. Their presence or absence influences the pretest probability of ST elevation on the electrocardiogram. The findings of this study may form the basis for larger trials to investigate the magnitude of this influence. A rapid but thorough history taking (which should be a part of pre-hospital care if possible and may form a reliable addition to existing focus of recognition of STEMI by paramedics [17, 18] can differentiate between patients whose pain is non-anginal and those who will require emergent life-saving interventions.

\section{Funding: Nil, Conflict of interest: None. Permission of IRB: Yes}

\section{References}

1. Hurst F. Hurst's The Heart. 13th ed. Furster Hurst KH, editor. USA: McGraw Hills and Sons; 20162016. $2258 \mathrm{p}$.

2. Malik MA, Alam Khan S, Safdar S, Taseer IU. Chest Pain as a presenting complaint in patients with acute myocardial infarction (AMI). Pak J Med Sci. 2013 Apr;29(2):565-8.

3. Peter Libby DM, Douglas Zipes, Robert Bonow. Braunwald Heart Disease. 10th ed. Braunwald E, editor. USA: Elsevier Saunders; 2016. $1931 \mathrm{p}$.

4. Bellolio MF, Sangaralingham LR, Schilz SR, NoelMiller CM, Lind KD, Morin P, Noseworthy PA, Shah $\mathrm{ND}$, Hess EP. Observation or inpatient: Impact of patient disposition on outcomes and utilization among emergency department patients with chest pain. Acad Emerg Med. 2016 Oct 14. doi: 10.1111/acem.13116. [Epub ahead of print].

5. Chandra A, Lindsell CJ, Limkakeng A, Diercks DB, Hoekstra JW, Hollander JE, et al. Emergency physician high pretest probability for acute coronary syndrome correlates with adverse cardiovascular outcomes. Acad Emerg Med. 2009;16(8):740-8.

6. Cubukcu A, Murray I, Anderson S. What's the risk? Assessment of patients with stable chest pain. Echo Res Pract. 2015 Jun 1;2(2):41-8. doi: 10.1530/ERP-14-0110. Epub 2015 Mar 9. 
7. Veronese G, Germini F, Ingrassia S, Cutuli O, Donati V, Bonacchini L, et al. Emergency physician accuracy in interpreting electrocardiograms with potential ST-segment elevation myocardial infarction: Is it enough? Acute Card Care. Published online 19 October 2016:pages 1-4. http://dx.doi.org/10.1080/ 17482941. 2016.1234058.

8. Cervellin G, Rastelli G. The clinics of acute coronary syndrome. Ann Transl Med. 2016 May;4(10):191. doi: 10.21037/atm.2016.05.10.

9. Davies N. Treating ST-elevation myocardial infarction. Emerg Nurse. 2016;24(3):20-5.

10. Pandie S, Hellenberg D, Hellig F, Ntsekhe M. Approach to chest pain and acute myocardial infarction. S Afr Med J. 2016 Mar;106(3):239-45.

11. Rabasse P, Johnson C, Malik N. NICE guidelines for new chest pain: comparison of new and old services. Br J Nurs. 2013 May 9-22;22(9):524-8.

12. Gokhroo RK, Ranwa BL, Kishor K, Priti K, Ananthraj A, Gupta S, et al. Sweating: A Specific Predictor of ST-Segment Elevation Myocardial Infarction Among the Symptoms of Acute Coronary Syndrome: Sweating In Myocardial Infarction (SWIMI) Study Group. Clin Cardiol. 2016;39(2):90-5.

13. Jones MM, Somerville C, Feder G, Foster G. Patients' descriptions of angina symptoms: a qualitative study of primary care patients. Br J Gen Pract. 2010 Oct;60(579):735-41. doi: 10.3399/bjgp10X532378.
14. Kirchberger I, Meisinger C, Heier M, Kling B, Wende R, Greschik C, von Scheidt W, Kuch B. Patientreported symptoms in acute myocardial infarction: differences related to ST-segment elevation: the MONICA/KORA Myocardial Infarction Registry. J Intern Med. 2011 Jul;270(1):58-64. doi: 10.1111/j. 1365-2796. 2011.02365.x. Epub 2011Mar 17.

15. Wah W, Pek PP, Ho AF, Fook-Chong S, Zheng H, Loy EY, Chua TS, Koh TH, Chow KY, Earnest A, Pang J, Ong ME. Symptom-to-door delay among patients with ST-segment elevation myocardial infarction in Singapore. Emerg Med Australas. 2016 Oct 11. doi: 10.1111/1742-6723.12689. [Epub ahead of print]

16. Garvey JL, Zegre-Hemsey J, Gregg R, Studnek JR. Electrocardiographic diagnosis of ST segment elevation myocardial infarction: An evaluation of three automated interpretation algorithms. J Electrocardiol. 2016;49(5):728-32.

17. Pilbery R, Teare MD, Goodacre S, Morris F. The Recognition of STEMI by Paramedics and the Effect of Computer inTerpretation (RESPECT): a randomised crossover feasibility study. Emerg Med J. 2016 Jul;33(7):471-6. doi: 10.1136/emermed-2015-204988. Epub 2016 Feb 10.

18. Savino PB, Sporer KA, Barger JA, Brown JF, Gilbert GH, Koenig KL, Rudnick EM, Salvucci AA. Chest Pain of Suspected Cardiac Origin: Current Evidence-based Recommendations for Prehospital Care. West J Emerg Med. 2015 Dec;16(7):983-95. doi: 10.5811/westjem.2015.8.27971. Epub 2015 Dec 11.

\section{How to cite this article?}

V.R. Mujeeb, Jambunathan P, Tyagi A. To study the correlation of symptoms of angina with the diagnosis of ST Segment Elevation Myocardial Infarction (STEMI). Int J Med Res Rev 2017;5(01):49-53. doi:10.17511/ijmrr. 2017.i01.07. 